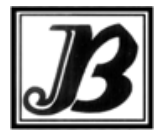

J. bio-sci. 17: 107-112, 2009

ISSN 1023-8654

http://www.banglajol.info/index.php/JBS/index

\title{
INCIDENCES OF BIRTH ABNORMALITIES, CONGENITAL DEFECTS AND THEIR ASSOCIATION WITH CONSANGUINEOUS MARRIAGES IN RAJSHAHI: A CASE STUDY
}

\author{
M Saiful Islam* Sharmin Ahmed \\ Department of Zoology, University of Rajshahi, Rajshahi 6205, Bangladesh
}

\begin{abstract}
Context: It has long been claimed that consanguineous marriages are deleterious to human well beings, but their association with incidences of birth abnormalities and congenital defects has not been well studied in our societies.

Objectives: To investigate frequencies of common birth abnormalities and congenital defects in children from congenital marriages in Rajshahi Metropolis areas.

Materials and Methods: A total of 150 clinical patients were chosen at random from 10 hospitals and clinics for recording their birth related abnormalities, whereas 281 children from 100 consanguineous couples from 17 Wards were included in the study for examining their congenital defects. All the patients, children and their parents were interviewed separately for recording the case histories.

Results: Frequencies of miscarriages (0.65), stillbirths (0.38), postnatal deaths $(0.30)$, and preterm deliveries (0.50) each in consanguineous cases differed significantly from that in non-consanguineous cases $(P<0.001)$. In addition, significantly shortened gestational ages $(34.37 \pm 4.08 w \mathrm{ws})$ and lower live birth weights $(3.20 \pm 0.72 \mathrm{~kg})$ prevailed in the children from consanguineous marriages $(P<0.001)$. Frequencies of six congenital defects in 76 children (30 females: 46 males) viz., deaf-mutism (0.70), cerebral palsy (0.12), mental retardation (0.11), blindness (0.04), syndactyly $(0.02)$ and deaf-mutism coupled with mental retardation (0.01), were recorded from 100 consanguineous couples who had a total of 281 children.
\end{abstract}

Conclusion: Demerits of the prevailing tradition of marrying close relatives in our society are obvious from the present results. Moreover, association between consanguinity and various birth and congenital malformations was statistically significant compared to the non-consanguineous cases.

Key words: Birth abnormalities, congenital defects, consanguineous marriages

\section{Introduction}

Congenital disorders refer to abnormalities, whether genetic or not, which are present at birth (Emery and Mueller 1992). In other words, malformations that may or may not be genetically determined, but may be due to environmental factors in utero, are said to be congenital. The most common congenital defects include cleft lips, cleft palates, club feet, microcephaly, blindness, deaf-mutism, mental retardations, polydactyly and other abnormalities of the limbs (Novitsky 1977).

A marriage between 'bloods relative' i.e. between persons who have one or more common ancestors is known as consanguineous marriage, which is usually a marriage between first cousins (Emery and Mueller 1992). Since cousins have one or both grandparents in common and if either of the two grandparents, maternal or paternal, carries a defective recessive gene, it stands a good chance of becoming homozygous in any one child who is a product of such consanguineous marriages (Novitsky 1977). The offspring of

•Corresponding author: saifulzoo@yahoo.co.uk 
consanguineous relationships are, therefore, at greater risk of certain genetic disorders. It is because closely related individuals have a higher chance of carrying the same alleles, deleterious or beneficial, than less closely related or unrelated individuals. Customs of laws, however, discourage or prohibit close relative marriages such as between sibs, between parent and child or between niece/nephew and uncle/aunt (Stern 1955). Snyder et al. (1985) estimated that the recessive genetic disorders in first cousin matings have a 10fold frequency $(1$ in 2,000) than the non-sanguineous matings $(1$ in 20,000). However, the risk of abnormalities depends on the degree of genetic relationship between the parents. For example, brothersister or father-daughter matings share $1 / 2$ or 0.5 of their DNA, compared to second cousin matings who share only $1 / 32$ or 0.03 of their DNA, although still much greater than the general population (Kingston 2002). A large majority of cases in post-World War II in Japan and the Indian subcontinent indicate that early mortality is increased in the progeny of consanguineous union when compared with children born to unrelated parents (Bittles et al. 2002, Bittles 2003).

Reports show that consanguinity increases the probability of detrimentally affected offspring in the population. Examples include pre- and postnatal deaths in babies from first cousin marriages (Morton 1958, 1961), hearing impairment and deaf-mutism (Ben Arab et al. 1990, Saggara and Bittles 2008) and blindness (Elder and De Cock 1993, Saggara and Bittles 2008). Children of consanguineous parents may be over represented in patients with severe mental retardation (Al-Hakeem and Hamamy 1992, Bener et al. 2007, Saggara and Bittles 2008). Substantially high proportions of recessively inherited mental and physical handicapped children resulted from consanguineous marriages in Iraq (Al-Hakeem and Hamamy 1992) and over $80 \%$ single gene autosomal recessive disorders and $22 \%$ congenital malformations were recorded among 16,419 births in Saudi Arabia (Al-Abdulkareem and Ballal 1998).

Recent studies with consanguineous marriages in India (Badaruddoza and Akhtaruzzaman 2007), Qatar (Bener et al. 2007), Lebanon (Ghina et al. 2007), Tunisia (Kerkeni et al. 2007), Jordan (Obeidat et al. 2008) and North Africa, the Middle East and large parts of Asia (Saggara and Bittles 2008) reveal some interesting results that have been dealt with later in Discussion. Here we report the incidences of various birth abnormalities and congenital defects in children from consanguineous unions in and around Rajshahi City Corporation areas.

\section{Materials and Methods}

Birth-related abnormalities: A total of 150 clinical patients, consisting of 40 consanguineous and 110 nonconsanguineous cases, were interviewed for their birth-related abnormalities namely miscarriages (spontaneous abortions), stillbirths, postnatal deaths, preterm deliveries and breech births. Moreover, the gestational ages and live birth weights of their latest babies were also recorded. The patients were chosen at random from the following 10 hospitals and clinics arranged alphabetically: Care Nursing Home, Christian Mission Hospital, Islami Bank Hospital, Mahanagar Clinic, Motherland Nursing Home, Mukti Clinic, Padma Clinic, Rajshahi Medical College Hospital, Sharmin Clinic and Zamzam Hospital situated within the Rajshahi City Corporation area.

Congenital defects: To gather information on various congenital defects among children, 100 consanguineous couples were traced out and contacted personally from the following 17 areas in the Rajshahi City Corporation (arranged alphabetically): Baya, Bhadra, Binodpur, Boharampur, Dorgapara, Horogram, Kadirganj, Kumarpara, Mohishbathan, Ramchandrapur, Ranibazar, Sadhurmore, Sagarpara, Sepaipara, Seroil, Sopura and Terokhadia. Of 281 children (115 females: 166 males) from 100 couples, 76 defective children (30 females: 46 males) came from 64 couples who were either paternal $(n=24)$, maternal $(n=18)$ or bi-parental $(n=22)$ cousins. 
Collection and analyses of data: Data on birth abnormalities viz., miscarriages (spontaneous abortions) or unexplained pregnancy losses, stillbirths, postnatal deaths, preterm deliveries, breech births, gestational ages (in wks), live birth weights (in $\mathrm{kg}$ ), and various congenital defects that have already been diagnosed clinically, were collected in a survey sheet designed for this experiment. All couples/mothers were interviewed separately for recoding their histories. The data were subjected to either chi-square or Student's t-tests as appropriate, and were analyzed using SPSS (version 11.5).

\section{Results}

Birth abnormalities: Effects of consanguineous marriages on some birth abnormalities recorded from 150 clinical cases are presented in Table 1. Results demonstrate that frequencies of miscarriages ( $0.65 \mathrm{vs}$. 0.24$)$, stillbirths (0.38 vs. 0.30$)$, postnatal deaths $(0.30$ vs. 0.23$)$ and premature babies $(0.50$ vs. 0.36$)$ were significantly greater in consanguineous marriages compared to the non-consanguineous counterparts $\left(\chi^{2}\right.$ values; $P<0.001$ for each). However, the incidence of breech births in non-consanguineous marriages was much higher than that in consanguineous marriages $(P<0.001)$. Apart from these parameters, both gestational ages ( $t=6.90 ; P<0.001$ at $148 \mathrm{df}$ ) and live birth weights ( $t=4.91 ; P<0.001$ at $148 \mathrm{df}$ ) of the children from consanguineous marriages were significantly lesser than the corresponding values recorded from the unrelated marriages.

Congenital defects: Of 281 children derived from 100 consanguineous couples, 76 were suffering from various congenital disorders (Table 2). The affected children came from 64 couples, the latter were significantly higher in number in comparison with 36 couples that did not produce any affected offspring $\left(\chi^{2}=\right.$ 7.84; $P<0.001$ at $1 \mathrm{df}$ ). A total of 216 children, 131 males and 85 females (sex-ratio $=1.54: 1.00$ ), came from 64 couples, whereas the remaining 36 couples had a total of 85 children ( 25 males and 30 females; sexratio= 1.17: 1.00). Gender-wise frequencies of the affected and normal children were $0.16,0.11,0.43$ and 0.30 , respectively, thus resulting in an over-all sex-ratio of 1.44 males to 1.00 females. Although the number of affected males $(n=46)$ did not differ statistically $\left(\chi^{2}=3.39 ; P>0.05\right.$ at $\left.1 \mathrm{df}\right)$ from the number of affected female children $(n=30)$, the total number of males $(n=166)$ were significantly higher $\left(\chi^{2}=9.26 ; P<0.001\right.$ at 1 df) than that of the females ( $n=115)$ born to 100 consanguineous couples.

In the present study, six congenital malformations were recognized from 76 affected children (Table 3). Of these, 30 came from paternal, 22 from maternal and 24 from bi- parental cousin marriages. Deaf and mute represented the highest frequency $(0.70 ; n=53)$, followed by cerebral palsy $(0.12 ; n=9)$, mental retardation $(0.11 ; n=8)$, blindness $(0.04 ; n=3)$, syndactyly $(0.02 ; n=2)$ and deaf-mute combined with mental retardation $(0.01 ; n=1)$.

\section{Discussion}

An early study by Morton (1958) in American population showed that birth defects owing to consanguinity include stillbirths and neonatal deaths $(0.111 \%)$ and infant and juvenile deaths $(0.156 \%)$. In addition, increased proportions of pre- and post-natal deaths ( $6 \%$ greater in each) in babies from first cousin marriages were recorded (Morton 1961). Hussain et al. (2001) noted consanguinity associated postnatal deaths in the first year of life in Muslim children from India and Pakistan. Multinational studies of over 600,000 pregnancies and live births in 10 populations from India (Bittles et al. 1991, Bittles and Neel 1994, Bittles 2002, 2003) show that postnatal deaths in 6 months to 10 year-old progenies from consanguineous marriages are $4.4 \%$ higher. A study by Kerkeni et al. (2007) revealed that spontaneous abortions, stillbirths, and neo- and postnatal deaths of children under 5 were significantly higher in consanguineous marriages in Tunisia. These findings are in good agreement with our results. Similar to the present data, Morton (1958) found shorter gestation length ( $<40.13$ wks) and Obeidat et al. (2008) recorded $12.3 \%$ preterm delivery in consanguineous 
cases. Moreover, reports indicate that significantly lighter birth weights in live born babies $(3.046 \mathrm{~kg}$ in America (Morton 1958); $1.8 \%$ less in Lebanon (Ghina et al. 2007) and 10.1\% low in Jordan (Obeidat et al. 2008) are common due to consanguinity. The present results indicate the devastating effects of marriages between close relatives on different birth abnormalities in Rajshahi.

Table 1. Birth abnormalities associated with consanguineous and non-consanguineous marriages recorded from 150 clinical cases in Rajshahi

\begin{tabular}{lccc}
\hline Birth abnormalities & $\begin{array}{c}\text { Consanguineous Marriages } \\
(\mathrm{n}=40)\end{array}$ & $\begin{array}{c}\text { Non-consanguineous } \\
\text { Marriages }(\mathrm{n}=110)\end{array}$ & Significance test Value \\
\hline Miscarriages & $26(0.65)$ & $26(0.24)$ & $29.39^{*}$ \\
Stillbirths & $15(0.38)$ & $32(0.29)$ & $16.49^{*}$ \\
Postnatal deaths & $12(0.30)$ & $25(0.23)$ & $13.36^{*}$ \\
Preterm deliveries & $20(0.50)$ & $40(0.36)$ & $22.27^{*}$ \\
Breech births & $10(0.25)$ & $40(0.36)$ & $11.57^{*}$ \\
Gestational ages (wks) & $34.37 \pm 4.08$ & $38.99 \pm 3.41$ & $6.90^{*}$ \\
Live birth weights $(\mathrm{kg})$ & $3.20 \pm 0.72$ & $4.26 \pm 1.28$ & $4.91^{*}$ \\
\hline Figures in parentheses indicate frequencies, ${ }^{*} \times 0.001$ & &
\end{tabular}

Table 2. Frequencies of affected versus normal children recorded from 100 consanguineous couples in Rajshahi

\begin{tabular}{|c|c|c|c|c|c|c|c|}
\hline \multirow{2}{*}{ Consanguineous Couples } & \multicolumn{2}{|c|}{ Affected children } & \multicolumn{2}{|c|}{ Normal children } & \multicolumn{2}{|c|}{ Total children } & \multirow{2}{*}{$\frac{\text { Sex-ratio }}{10: 9}$} \\
\hline & $0^{1}$ & q & $\hat{0}$ & 9 & 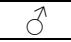 & क & \\
\hline 34 & 46 & 30 & 85 & 55 & 131 & 85 & $1.54: 1$ \\
\hline 36 & 0 & 0 & 35 & 30 & 35 & 30 & 1.17:1 \\
\hline 100 & 46 & 30 & 110 & 85 & 166 & 115 & $1.44: 1$ \\
\hline Frequency & 0.16 & 0.11 & 0.43 & 0.30 & 0.59 & 0.41 & \\
\hline
\end{tabular}

Table 3. Frequencies of various congenital defects in 76 affected children from 64 consanguineous couples in Rajshahi

\begin{tabular}{|c|c|c|c|c|c|c|c|c|}
\hline \multirow{2}{*}{ Consanguineous Couples } & \multirow{2}{*}{$\begin{array}{c}\text { Type of } \\
\text { consanguinity* }\end{array}$} & \multicolumn{6}{|c|}{ Congenital disorders } & \multirow{2}{*}{$\begin{array}{l}\text { Total Affected } \\
\text { children }\end{array}$} \\
\hline & & DM & $\mathrm{CP}$ & MR & $\mathrm{BL}$ & SD & $\mathrm{DM}+\mathrm{BL}$ & \\
\hline 24 & Paternal cousin & 22 & 4 & 3 & 1 & 0 & 0 & 30 \\
\hline 18 & Maternal cousin & 15 & 2 & 2 & 2 & 1 & 0 & 22 \\
\hline 22 & Bi-parental cousin & 16 & 3 & 3 & 0 & 1 & 1 & 24 \\
\hline 64 & & 53 & 9 & 8 & 3 & 2 & 1 & 76 \\
\hline Frequency & & 0.70 & 0.12 & 0.11 & 0.04 & 0.02 & 0.01 & 1.00 \\
\hline
\end{tabular}

*Paternal cousins= Sons and daughters of two full brothers; Maternal cousins= Sons and daughters of two full sisters; Bi-parental cousins= Sons and daughters of a sister and her brother belonging to the same parents. $D M=$ Deaf -mute; $C P=$ Cerebral palsy; $M R=$ Mentally retarded; $B L=B l i n d ; S D=$ Syndactylous; DD+BL= Deaf-mute and blind.

Ben Arab et al. (1990) reported hearing impairment and deafness in children from consanguineous marriages. In addition, hearing loss, blindness, congenital glaucoma, cerebral lipidoses, mental retardation associated with decreased IQ scores and increased levels of intellectual disabilities are common in first cousin marriages compared to the non-consanguineous unions (Bittles 2002, 2003, Bittles et al. 2002). According to a recent investigation, deafness and retinal dystrophies leading to blindness are prevalent in the children from first cousin marriages in North Africa, the Middle East and large parts of Asia due to the expression of detrimental recessive genes (Saggara and Bittles 2008).

As regards the incidences of various congenital defects in children from consanguineous couples, AlHakeem and Hamamy (1992) found substantially high proportions of recessively inherited mental and physical handicapped children in Iraq. Childhood blindness was found to be associated with consanguinity in 
the West Bank and Gaza Strip population (Elder and De Cock 1993). Al-Abdulkareem and Ballal (1998) reported $80 \%$ single-gene autosomal recessive disorders and $22 \%$ congenital malformations in 16,419 babies from consanguineous couples in the urban areas of Saudi Arabia. Modell and Darr (2002) noticed increased birth prevalence of infants with severe recessive disorders in consanguineous marriages. While syndactyly or webbed fingers is reported to be the most common congenital malformation of the limbs and the condition occurs about 1 in every 2000-3000 live births, it is twice as common in males, and is 10 times more common in whites than blacks (Flatt 2005, Mandal et al. 2008). Bener et al. (2007) showed higher rates of mental disorders and hearing deficit in children from first-cousins in the urban and semi-urban areas of Qatar. An appreciably high proportion of children (4.1\%) from first-cousin marriages in Jordan suffered from congenital anomalies (Obeidat et al. 2008). The present results conform to the above findings in that relatively high proportions of the deaf-mutism $(70 \%)$, cerebral palsy $(12 \%)$, mental retardation $(11 \%)$, blindness $(4 \%)$ and syndactyly (2\%) appeared in offspring from consanguineous couples in Rajshahi. Considering the small sample size ( $n=281$ children from 100 consanguineous couples), the frequencies of congenital defects in urban Rajshahi appeared to be too high.

\section{Conclusion}

Since association between consanguinity and various birth and congenital malformations were statistically significant compared to the non-consanguineous marriages, this case study clearly demonstrate the negative and harmful impacts of marriages between close relatives on immediate progenies. The present results therefore emphasize the importance of genetic counseling for the prospective couples in our society to avoid such familial disasters.

\section{Acknowledgement}

This forms a part of MSc Thesis by SA. The authors would like to thank the patients and consanguineous couples for providing their personal and familial information required for this research. Physician and health workers also deserve special mention for their cooperation.

\section{References}

Al-Abdulkareem AA, Ballal SG. 1998. Consanguineous marriage in an urban area of Saudi Arabia: rates and adverse health effects on the offspring. J Com Health 23, 75-83. doi:10.1023/A:1018727005707

Al-Hakeem S, Hamamy H. 1992. Genetic studies on institutionalized mentally retarded males with special reference to fragile X syndrome. Unpubl. MSc Thesis, Al-Mustansiriyah Medical College, Bagdad, Iraq.

Badaruddoza MA, Akhtaruzzaman M. 2007. Inbreeding and congenital heart diseases in a north Indian population. Croat Med J 48(5), 701-707.

Ben Arab S, Bonaiti-Pellie C, Belkahia A. 1990. An epidemiological and genetic study of congenital profound deafness in Tunisia (Governorate of Nabeul). J Med Genet 27(1), 29-33. doi:10.1136/jmg.27.1.29

Bener A, Hussain R, Teebi AS. 2007. Consanguineous marriages and their effects on common adult diseases: Studies from an endogamous population. Med Princ Pract 16, 262-267. doi:10.1159/000102147

Bittles AH. 2002. The impact of consanguinity on the Indian population. Indian J Human Genet 8, 45-51.

Bittles AH. 2003. Consanguineous marriage and childhood health. Dev Med Child Neurol 45(8), 571-576. doi:10.1111/j.1469-8749.2003.tb00959.x

Bittles AH, Neel JV. 1994. The costs of human inbreeding and their implications for variations at the DNA level. Nature Genet 8, 117-121. doi:10.1038/ng1094-117

Bittles AH, Mason WM, Greene J, Appaji RN. 1991. Reproductive behavior and health in consanguineous marriages. Science 252, 789-794. doi:10.1126/science.2028254 
Bittles AH, Grant JC, Sullivan SG, Hussain R. 2002. Does inbreeding lead to decreased human fertility? Ann Hum Biol 29, 111-130. doi:10.1080/03014460110075657

Elder MJ, De Cock R. 1993. Childhood blindness in the West Bank and Gaza Strip: Prevalence, etiology and hereditary factors. Eye 7, 580-583.

Emery AEH, Mueller RF. 1992. Elements of Medical Genetics (8 $8^{\text {th }}$ edn.). Longman Group UK Ltd. 349 pp.

Flatt AE. 2005. Webbed fingers. Proc Bayl Univ Med Cent 18(1), 26-37.

Ghina M, Hala T, Mona K, Marwan K, Mustafa K, Gerard W, Yunis KA. 2007. Effect of consanguinity on birth weight for gestational age in a developing country. Am J Epidemiol 165(7), 742-752. doi:10.1093/aje/kwk108

Hussain R, Bittles AH, Sullivan S. 2001. Consanguinity and early mortality in the Muslim populations of India and Pakistan. Am J Hum Biol 13, 777-787. doi:10.1002/ajhb.1124

Kerkeni E, Monastiri K, Seket B, Guediche MN, Cheikh HB. 2007. Interplay of socio-economic factors, consanguinity, fertility, and offspring mortality in Monastir, Tunisia. Croat Med J 48(5), 710-717.

Kingston HM. 2002. ABC of Clinical Genetics (3rd edn.). BMJ Books, London. 533 pp.

Mandal K, Phadke SR, Kalita J. 2008. Congenital swan neck deformity of fingers with syndactyly. Clin Dysmorphol 17(2), 109-111. doi:10.1097/MCD.0b013e3282f5280f

Modell B, Darr A. 2002. Science and Society: Genetic counseling and customary consanguineous marriage. Nature Rev Genet 3, 225-229. doi:10.1038/nrg754

Morton NE. 1958. Empirical risks in consanguineous marriages: Birth weight, gestation time and measurement of infants. Am J Hum Genet 1, 344-349.

Morton NE. 1961. Morbidity of children from consanguineous marriages. Prog Med Genet 1, 261-291.

Novitsky E. 1977. Human Genetics. Mcmillan Publ. Co. Inc., New York, USA. 458 pp.

Obeidat BR, Khader YS, Amarin ZO, Kassawneh M, Omari MA. 2008. Consanguinity and adverse pregnancy outcomes: The North of Jordan experience. Mat Child Health J 14, 232-240.

Saggara RA, Bittles AH. 2008. Consanguinity and child health. Paed Child Health 18(5), 244-249. doi:10.1016/j.paed.2008.02.008

Snyder LA, David F, Daniel LH. 1985. General Genetics. Jones \& Barttett Publ. Inc. Boston, USA. 525 pp.

Stern C. 1955. Principles of Human Genetics. WH Freeman \& Co. USA. 635 pp. 